\title{
An Updated View on the Molecular Pathomechanisms of Human Dihydrolipoamide Dehydrogenase Deficiency in Light of Novel Crystallographic Evidence
}

\author{
Attila Ambrus ${ }^{1}$ iD \\ Received: 2 December 2018 / Revised: 25 February 2019 / Accepted: 26 February 2019 / Published online: 7 March 2019 \\ (c) The Author(s) 2019
}

\begin{abstract}
Dihydrolipoamide dehydrogenase (LADH, E3) deficiency is a rare (autosomal, recessive) genetic disorder generally presenting with an onset in the neonatal age and early death; the highest carrier rate has been found among Ashkenazi Jews. Acute clinical episodes usually involve severe metabolic decompensation and lactate acidosis that result in neurological, cardiological, and/or hepatological manifestations. Clinical severity is due to the fact that LADH is a common E3 subunit to the alpha-ketoglutarate, pyruvate, alpha-ketoadipate, and branched-chain alpha-keto acid dehydrogenase complexes, and is also a constituent in the glycine cleavage system, thus a loss in LADH function adversely affects multiple key metabolic routes. However, the severe clinical pictures frequently still do not parallel the LADH activity loss, which implies the involvement of auxiliary biochemical mechanisms; enhanced reactive oxygen species generation as well as affinity loss for multienzyme complexes proved to be key auxiliary exacerbating pathomechanisms. This review provides an overview and an up-to-date molecular insight into the pathomechanisms of this disease in light of the structural conclusions drawn from the first crystal structure of a disease-causing hE3 variant determined recently in our laboratory.
\end{abstract}

Keywords Dihydrolipoamide dehydrogenase $\cdot$ E3 deficiency $\cdot$ Alpha-ketoglutarate dehydrogenase complex $\cdot$ Pyruvate dehydrogenase complex $\cdot$ Pathogenic mutation $\cdot$ Reactive oxygen species (ROS) $\cdot$ X-ray crystallography $\cdot$ Structure

\section{E3 Deficiency-the Disease, Enzyme, and Affected Multienzyme Complex Functions}

(Dihydro)lipoamide dehydrogenase (LADH, E3; gene: dld) deficiency is an often prematurely lethal rare autosomal recessive genetic disorder [1]; the highest carrier rate (1:94-1:110, G194C-hE3, $\mathrm{h}$ for human) has been found among Ashkenazi Jews with a disease frequency of 1:35,000-1:48,000 [2, 3]. The first and sole review on the molecular pathomechanisms of this disease was written by our laboratory [4]. This disorder involves mainly neurological, cardiological, and hepatological manifestations whose

Special Issue: In honor of Prof. Vera Adam-Vizi.

Attila Ambrus

ambrus.attila@med.semmelweis-univ.hu

1 Department of Medical Biochemistry, MTA-SE Laboratory for Neurobiochemistry, Semmelweis University, 37-47 Tuzolto Street, Budapest 1094, Hungary symptoms generally arise very early in life. The phenotypic spectrum includes hyperammonemia, failure to thrive, hypotonia, encephalopathy, seizure, hepatomegaly, liver dysfunction, lactate acidosis, hypoglycemia, Leigh syndrome, developmental delay, hypertrophic cardiomyopathy, vision impairment/optic atrophy, ataxia, and microcephaly, among others [1, 3, 5-16]. Potentially lethal hepatological consequences, often together with encephalopathy and coagulopathy, may present in isolation and in adulthood [3, 17-19]. The severity of the clinical outcomes is due to the simultaneous defects of the mitochondrial E3-harboring multienzyme dehydrogenase complexes for alpha-ketoglutarate (KGDHc), pyruvate (PDHc), alpha-ketoadipate (KADHc), and branched-chain alpha-keto acids (BCKDHc); interestingly, the glycine cleavage system (GCS), which also contains the LADH protein, remains unaffected in E3-deficiency $[1,4,20-22]$. In the above dehydrogenase complexes the common E3 subunit catalyzes the re-oxidation of the dihydrolipoate (DHLA) moieties covalently linked to the respective $\mathrm{E} 2$ components and the reduction of $\mathrm{NAD}^{+}$to NADH (LADH activity, forward reaction). Pathogenic gene variants 
include missense or nonsense mutations, splice site variants, and ones with (small) deletions/insertions; 14 diseasecausing enzyme variants have been reported to date in the clinical literature $[4,6,8]$.

\section{Auxiliary Exacerbating Pathomechanisms}

Clinical severity, more often than not, does not parallel the loss in LADH activity [4, 6, 8, 13, 20, 23, 24]. Recent results suggest that the missing clues could be (i) enhanced reactive oxygen species (ROS) production by various pathogenic $\mathrm{hE} 3$ mutants [20, 23, 24], particularly in acidosis [24], (ii) liberation of selected hE3 variants from the E3-tethering multienzyme complexes [25-29], and (iii) ROS generation by the E1-E2 subcomplex of the hKGDHc (when E3 is scarce) [20], principally in the course of acidosis [30].

\section{ROS Generation by hE3, Pathogenic hE3 Mutants, and $\mathrm{hE3}$-Harboring Multienzyme Complexes}

Among all the mitochondrial alpha-keto (or 2-oxo) acid dehydrogenase complexes (OADHc), the KGDHc exhibits the most dominant ROS generation under pathologically relevant conditions [20-22, 31-42]. ROS generation by the KGDHc can occur in the forward catalytic direction in case the physiological electron acceptor $\mathrm{NAD}^{+}$is scarce or absent (in vitro), or alternatively in the reverse reaction driven by a high NADH/NAD ${ }^{+}$ratio [20, 30, 33, 34]; superoxide (as a primary ROS) is generated at the flavoenzyme E3 component [20, 33, 34] (see Scheme 1). The isolated E3 component $[43,44]$ is also capable of generating ROS, in an oxidase reaction, in either direction of the catalytic reaction [20, 24, 30, 45-51] (Scheme 1). The E3 subunit forms a functional (obligate), non-covalent homodimer that uses residues from both monomers for the physiological LADH activity [45, 52-55], but not for the ROS-generating activity [56-58]; hE3 comprises four domains: a FAD-binding (1-149), a NAD ${ }^{+} / \mathrm{NADH}$-binding (150-282), a central (283-350), and an interface domain (351-474). ROS generation in the reverse reaction of the isolated E3 component is stimulated in acidosis; this same pathological condition also enhances the ROS production in the reverse, but not in the forward reaction of KGDHc [30]. Sensitivity to a decreasing $\mathrm{pH}$ of ROS-generation by isolated disease-causing $\mathrm{hE} 3$ mutants that display increased ROS-generating capacities in the reverse reaction was reported to be even more pronounced [24]; pathogenic substitutions which stimulated ROS production took place at the disulfide-exchange site (P453L), the dimerization surface (E340K, D444V), or the cofactor-binding site (G194C) [24]. Calibrated gel filtration, molecular dynamics (MD) simulation, hydrogen-deuterium exchange mass spectrometry (HDX-MS), diffusion-ordered (DOSY) NMR, (soft-ionizing) nano-LC MS, and X-ray crystallography (see below) all confirmed that neither (mild) acidosis nor the hitherto investigated disease-causing homodimerization surface mutations led to monomerization of the E3 dimer [24, 25, 30, 59-62]. Importantly, ROS production could also be stimulated by a relevant disease-causing $\mathrm{hE} 3$ mutant (G194C-hE3) when complexed to a multienzyme complex (hKGDHc) [20]. The D444V-, G194C-, E340K-, R460G-, and R447G-hE3 pathogenic mutants were reported to oxidatively deteriorate the lipoic acid (LA) cofactors of the PDHc and KGDHc in a yeast model, and in case of D444V-hE3, in human homozygous fibroblasts [23]. In mutants exhibiting stimulated ROS production, LADH activity was generally impaired in both catalytic directions. In P453L-hE3 the physiological activity was almost entirely lost while the ROS-generating activity became predominant, whereas in G194C-hE3 the LADH activity was not altered, but the ROS-producing capacity increased [24]. For P453L$\mathrm{hE} 3$ the clinical phenotype was very severe $[16,63]$ and the excessive ROS production was proposed to be a contributing factor to this [24]. G194C-hE3 leads often to adult-onset manifestations, which is in accord with the retained LADH activity and the moderately enhanced ROS generation [24]. FAD contents were almost entirely retained in D444V-hE3 and E340K-hE3, while G194C-hE3 and P453L-hE3 exhibited $30 \%$ loss of FAD [24]. Circular dichroism (CD) spectroscopy represented no significant overall structural alterations in the above four mutants [24]. HDX-MS however detected significant changes in flexibility/exposure in the lipoic acid (LA) binding channel of P453L-hE3 and G194C$\mathrm{hE3}$, which could potentially result in stimulation of ROS production. HDX-MS data for D444V-hE3 and E340K-hE3 were rather inconclusive in terms of the mechanism of action
Scheme 1 Forward, reverse, and ROS-generating reactions of LADH
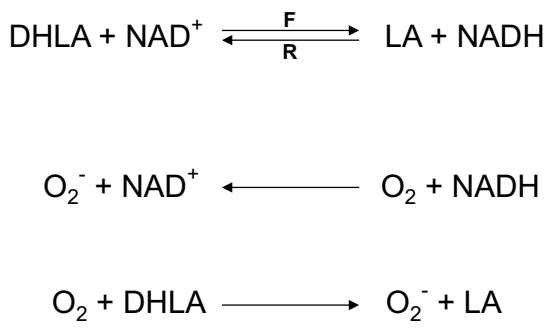

forward $(F)$ and reverse $(R)$ reactions with physiological substrates (LADH/OADHc)

reverse ROS-generating reaction (LADH/KGDHc)

forward ROS-generating reaction (LADH/KGDHc/hKGDHc-E1E2) 
of increased ROS production [25]. MD simulation of 13 disease-causing hE3 mutants was also carried out $[59,60]$; good correlation with HDX-MS results was reported for the P453L, K37E, G194C, I445M, and R460G substitutions [4].

\section{Conclusions of the First Disease-Causing Mutant Structure (D444V-hE3) Relevant to Compromised Enzymatic Activity and ROS Generation}

Crystal structures have been published for hE3 [28, 29, 52, $61,64]$ and now also for the D444V-hE3 disease-causing mutant from our laboratory [61]. High-resolution crystal structures have very recently been determined in our laboratory also for the P453L- (PDB ID: 6I4Z), G194C- (PDB ID: 6I4P), R460G- (PDB IDs: 6I4R and 6HG8), R447G- (PDB ID: 6I4S), I445M- (PDB ID: 6I4T), and G426E-hE3 (PDB ID: $6 \mathrm{I} 4 \mathrm{U}$ ) disease-causing variants and for hE3 at the hitherto highest $1.75 \AA$ resolution (PDB ID: 6I4Q), however, the thorough and comparative analysis of these structures is still in progress. The already published and analyzed D444V-hE3 crystal structure demonstrated a shorter and wider $\mathrm{H}^{+} / \mathrm{H}_{2} \mathrm{O}$ releasing channel when compared to the wild type structure. This channel is solvent accessible, leads to the active site and it is the continuation of the LA-binding substrate channel (Fig. 1); the $\mathrm{H}^{+} / \mathrm{H}_{2} \mathrm{O}$ channel appears to have catalytic roles in LADH function and perhaps ROS generation by hE3 [61]. A drop in surface potential around the exit of this channel was also found when compared to the hE3 structure. Several helices and random coils form the above channel, the helices all pointing with the positive ends of their dipoles towards the active site; structural alterations in the channel-forming helices likely affect the active site via relayed helix dipole moment contributions. All the above mentioned structural alterations in D444V-hE3 hence indeed may lead to a drop in enzyme activity and the positive shift in ROS-generating capacity [61]. Another indirect effect that might also have contribution to the pathological behaviors is an overall change in penetration through the channel upon structural changes, which was suggested altering the apparent redox potential of the FAD moiety $[65,66]$; the redox status of FAD has direct influence on both the regular catalytic and ROS-generating activities. The C-terminus in D444V-hE3 was shown by HDX-MS to possess higher flexibility as compared to hE3 [25]; this effect could not be detected by crystallography, perhaps due to the cryogenic conditions. Since the C-terminus separates and hence forms connection between the LA-binding and the $\mathrm{H}^{+} / \mathrm{H}_{2} \mathrm{O}$ channels, any change in this region might also affect the LA-binding substrate channel, which is also implicated in both the normal catalytic action as well as superoxide generation [25, 61]. Since the disease-causing dimer interface substitutions (D444V, E340K, R447G, R460G, I445M) all take place in the vicinity of the $\mathrm{H}^{+} / \mathrm{H}_{2} \mathrm{O}$ channel (Fig. 2), considerably far from the LA-binding channel, the cofactor-binding sites, and the active site, this channel was connected to the potential existence of a generalized pathomechanism of human E3-deficiency for the disease-causing dimerization interface mutations [61].

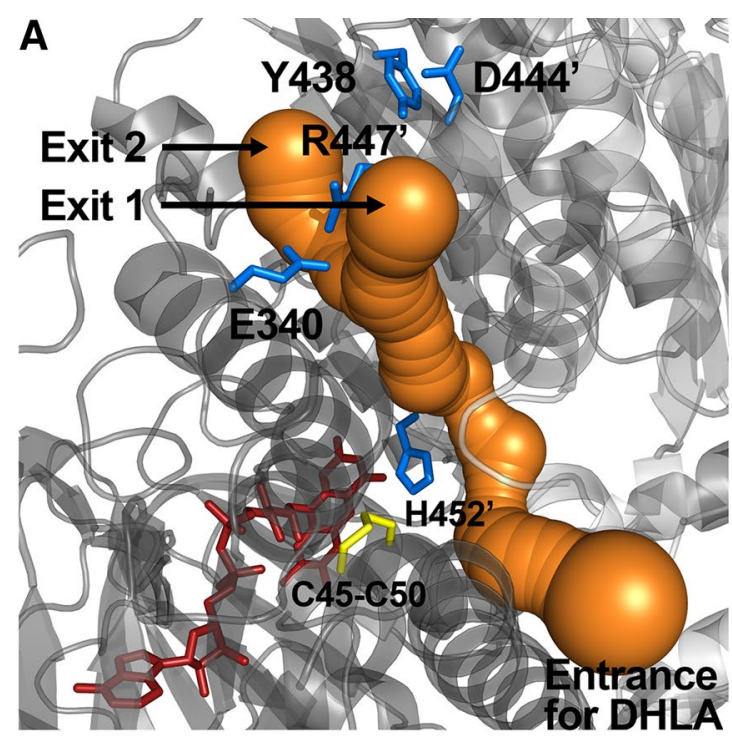

Fig. 1 The $\mathrm{LA}(/ \mathrm{DHLA})$-binding and $\mathrm{H}^{+} / \mathrm{H}_{2} \mathrm{O}$ channels in the A-B dimers of hE3 (A, PDB ID: 5NHG) and D444V-hE3 (B, PDB ID: $5 \mathrm{~J} 5 \mathrm{Z}$ ). Monomer A is labeled in both proteins. The redox-active $\mathrm{C} 45$ -

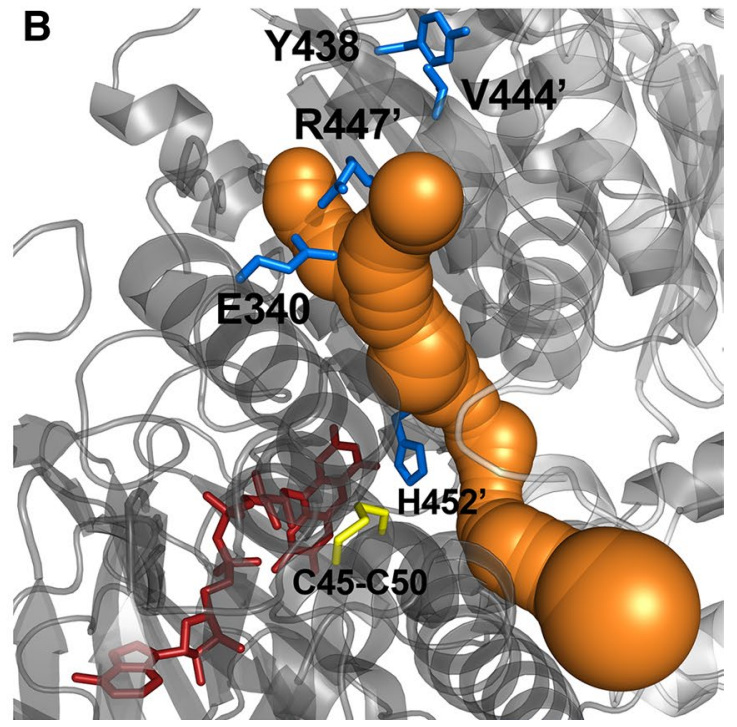

C50 pair and FAD are represented as yellow and red sticks, respectively. (Color figure online) 


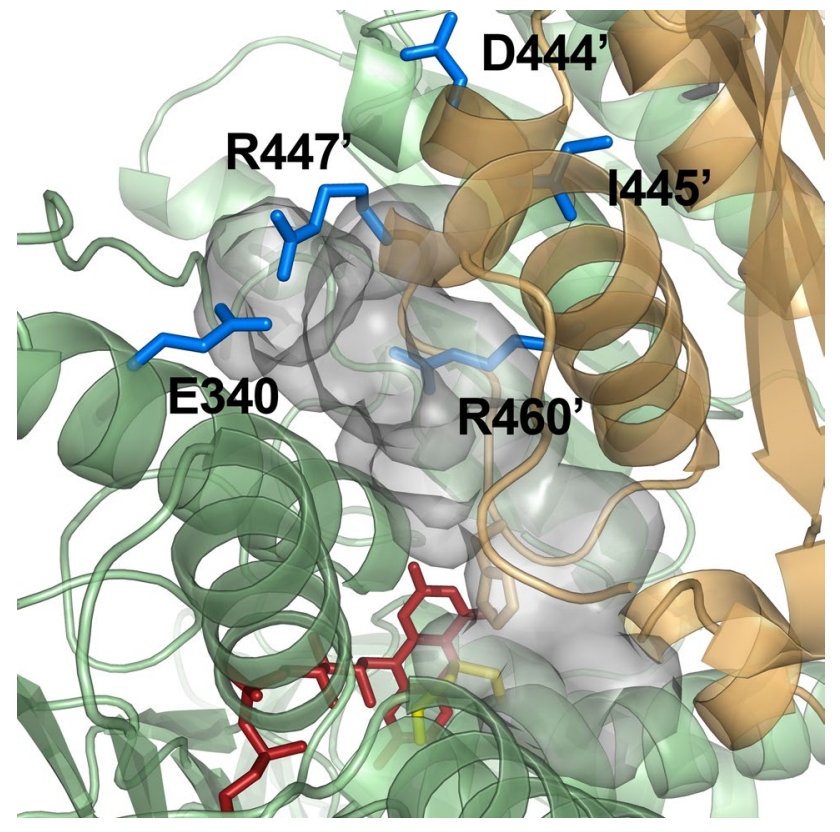

Fig. 2 Pathogenic amino acid substitution sites near the $\mathrm{H}^{+} / \mathrm{H}_{2} \mathrm{O}$ channel in the hE3 crystal structure (PDB ID: 5NHG). The inner surface of the channel is displayed (A-B dimer). The C45-C50 pair and FAD are colored as for Fig. 1. (Color figure online)

\section{Affinity Loss for Multienzyme Complexes and Respective Structural Conclusions for D444V-hE3}

The affinity of E3 for the KGDHc proved to be low [67-69] and even lower in acidosis [30]; E3 binds 30 times stronger to the PDHc [68, 70, 71]. Several experimental evidence suggest that E1, and not E2, would directly bind E3 in the KGDHc [72-74]. LADH can also exist as a liberated protein in vivo $[30,68,75-78]$; it is the most abundant flavoprotein in brain and muscle mitochondria [79]. Several disease-causing hE3 variants (R447G-, D444V-, R460G-, and E340K$\mathrm{hE3}$ ) exhibit significantly impaired affinity for the hPDHc leading to greatly compromised overall hPDHc activities [25-27, 29]. The D444V-hE3 crystal structure demonstrated a drop in surface potential over the entire protein molecule, while HDX-MS showed an enhanced flexibility on the surface where the E3-binding protein (E3BP) of hPDHc is tethered [25, 61]; both effects likely contribute to the compromised affinity for hPDHc. The D444V-hE3 crystal structure also confirmed previous experimental data on the lack of monomerization and FAD loss in this mutant [61].

\section{ROS Generation by the E1-E2 Subcomplex of the hKGDHc}

In case hE3 is untethered from the hKGDHc, as is likely the case for several pathogenic variants and in acidosis, the E1-E2 subcomplex is potentially also capable of generating ROS at a very considerable rate in the forward catalytic direction [20] (Scheme 1). Thus, under such conditions, ROS production might proceed simultaneously from E3 (principally in the reverse catalytic direction) as well as from the E1-E2 subcomplex (in the forward catalytic direction), provided that substrate provision is sufficient [4, 20]; an intact population of KGDHc may still retain some overall activity [6], unless the LA prosthetic group suffers oxidative damage [23]. Since the E2 (dihydrolipoamide succinyltransferase) component could potentially also be targeted against ROS generation, we very recently determined its cryo-electronmicroscopic structure; we were able to detect residues $218-453$ at $3.31 \AA$ resolution (PDB ID: 6H05), which in a further and still progressing stage of structure determination appears to develop to be $2.9 \AA$ resolution (unpublished result).

\section{Conclusions}

In conclusion, human E3-deficiency is still an incurable and hardly manageable disease, which might be taken under better control by dietary restrictions, nutritional support, correction of metabolic acidosis and coagulopathy, administration of flavins, lipoic acid, thiamine, trial of dichloroacetate, for selected and respective cases [1, 4]. Since in many cases with impaired affinity for multienzyme complexes the residual hE3 activity is much higher than the residual overall multienzyme complex activity, with the high-resolution crystal structures in hand, adaptor molecules could potentially be developed to retether the respective pathogenic hE3 mutants to their harboring multienzyme complexes; although this might only be a limited therapeutic solution, the approach can potentially be advantageous for selected patients. Development of specific ROS generation inhibitors against selected hE3 mutants and the E2 subunit of the hKGDHc, besides a general antioxidant therapy, might also be a valid approach towards possible therapeutic solutions. Besides gene therapy, which still requires substantial development to be efficient and completely safe, enzyme replacement therapy might gain potentials in the treatment of human E3 deficiency in the near future $[80,81]$.

Acknowledgements Open access funding provided by Semmelweis University (SE). Financial support is acknowledged from the Hungarian Academy of Sciences (MTA Grant 02001 to Vera Adam-Vizi), the Hungarian Scientific Research Fund (OTKA Grant 112230 to V.A.-V.), and the Hungarian Brain Research Program (Grant 2017-1.2.1-NKP2017-00002 to V.A.-V.). The author thanks Eszter Szabo for the figures and her valuable comments and Prof. Vera Adam-Vizi for her long time support. 


\section{Compliance with Ethical Standards}

Conflict of interest The authors declare no conflict of interest.

Open Access This article is distributed under the terms of the Creative Commons Attribution 4.0 International License (http://creativeco mmons.org/licenses/by/4.0/), which permits unrestricted use, distribution, and reproduction in any medium, provided you give appropriate credit to the original author(s) and the source, provide a link to the Creative Commons license, and indicate if changes were made.

\section{References}

1. Quinonez SC, Thoene JG (2014) Dihydrolipoamide Dehydrogenase Deficiency. In: Pagon RA, Adam MP, Ardinger HH et al (ed) GeneReviews ${ }^{\circledR}$ [Internet] 1993-2016. University of Washington, Seattle, Seattle (WA) pp 1-37

2. Scott SA, Edelmann L, Liu L, Luo MJ, Desnick RJ, Kornreich R (2010) Experience with carrier screening and prenatal diagnosis for 16 Ashkenazi Jewish genetic diseases. Hum Mutat $31: 1240-1250$

3. Shaag A, Saada A, Berger I, Mandel H, Joseph A, Feigenbaum A, Elpeleg ON (1999) Molecular basis of lipoamide dehydrogenase deficiency in Ashkenazi Jews. Am J Med Genet 82:177-182

4. Ambrus A, Adam-Vizi V (2018) Human dihydrolipoamide dehydrogenase (E3) deficiency: novel insights into the structural basis and molecular pathomechanism. Neurochem Int 117:5-14

5. Carrozzo R, Torraco A, Fiermonte G, Martinelli D, Di Nottia M, Rizza T, Vozza A, Verrigni D, Diodato D, Parisi G, Maiorana A, Rizzo C, Pierri CL, Zucano S, Piemonte F, Bertini E, Dionisi-Vici C (2014) Riboflavin responsive mitochondrial myopathy is a new phenotype of dihydrolipoamide dehydrogenase deficiency. The chaperon-like effect of vitamin B2. Mitochondrion 18:49-57

6. Quinonez SC, Leber SM, Martin DM, Thoene JG, Bedoyan JK (2013) Leigh syndrome in a girl with a novel DLD mutation causing E3 deficiency. Pediatr Neurol 48:67-72

7. Quintana E, Pineda M, Font A, Vilaseca MA, Tort F, Ribes A, Briones P (2010) Dihydrolipoamide dehydrogenase (DLD) deficiency in a Spanish patient with myopathic presentation due to a new mutation in the interface domain. J Inherit Metab Dis 33:S315-S319

8. Cameron JM, Levandovskiy V, MacKay N, Raiman J, Renaud DL, Clarke JTR, Feigenbaum A, Elpeleg O, Robinson BH (2006) Novel mutations in dihydrolipoamide dehydrogenase deficiency in two cousins with borderline-normal PDH complex activity. Am J Med Genet A 140A:1542-1552

9. Odievre MH, Chretien D, Munnich A, Robinson BH, Dumoulin R, Masmoudi S, Kadhom N, Rötig A, Rustin P, Bonnefont JP (2005) A novel mutation in the dihydrolipoamide dehydrogenase E3 subunit gene (DLD) resulting in an atypical form of alphaketoglutarate dehydrogenase deficiency. Hum Mutat 25:323-324

10. Hong YS, Korman SH, Lee J, Ghoshal P, Qu Q, Barash V, Kang S, Oh S, Kwon M, Gutman A, Rachmel A, Patel MS (2003) Identification of a common mutation (Gly194Cys) in both Arab Moslem and Ashkenazi Jewish patients with dihydrolipoamide dehydrogenase (E3) deficiency: possible beneficial effect of vitamin therapy. J Inherit Metab Dis 26:816-818

11. Grafakou O, Oexle K, van den Heuvel L, Smeets R, Trijbels F, Goebel HH, Bosshard N, Superti-Furga A, Steinmann B, Smeitink J (2003) Leigh syndrome due to compound heterozygosity of dihydrolipoamide dehydrogenase gene mutations. Description of the first E3 splice site mutation. Eur J Pediatr 162:714-718
12. Cerna L, Wenchich L, Hansiková H, Kmoch S, Peskova K, Chrastina P, Brynda J, Zeman J (2001) Novel mutations in a boy with dihydrolipoamide dehydrogenase deficiency. Med Sci Monitor 7:1319-1325

13. Shany E, Saada A, Landau D, Shaag A, Hershkovitz E, Elpeleg ON (1999) Lipoamide dehydrogenase deficiency due to a novel mutation in the interface domain. Biochem Biophys Res Commun 262:163-166

14. Hong YS, Kerr DS, Liu TC, Lusk M, Powell BR, Patel MS (1997) Deficiency of dihydrolipoamide dehydrogenase due to two mutant alleles (E340K and G101del) - analysis of a family and prenatal testing. Biochim Biophys Acta-Mol Basis Dis 1362:160-168

15. Hong YS, Kerr DS, Craigen WJ, Tan J, Pan YZ, Lusk M, Patel MS (1996) Identification of two mutations in a compound heterozygous child with dihydrolipoamide dehydrogenase deficiency. Hum Mol Genet 5:1925-1930

16. Liu TC, Kim H, Arizmendi C, Kitano A, Patel MS (1993) Identification of two missense mutations in a dihydrolipoamide dehydrogenase-deficient patient. Proc Natl Acad Sci USA 90:5186-5190

17. Brassier A, Ottolenghi C, Boutron A, Bertrand AM, ValmaryDegano S, Cervoni JP, Chretien D, Arnoux JB, Hubert L, Rabier D, Lacaille F, de Keyzer Y, Di Martino V, de Lonlay P (2013) Dihydrolipoamide dehydrogenase deficiency: a still overlooked cause of recurrent acute liver failure and Reye-like syndrome. Mol Genet Metab 109:28-32

18. Barak N, Huminer D, Segal T, Ben Ari Z, Halevy J, Kaspa RT (1998) Lipoamide dehydrogenase deficiency: a newly discovered cause of acute hepatitis in adults. J Hepatol 29:482-484

19. Elpeleg ON, Saada AB, Shaag A, Glustein JZ, Ruitenbeek W, Tein I, Halevy J (1997) Lipoamide dehydrogenase deficiency: a new cause for recurrent myoglobinuria. Muscle Nerve 20:238-240

20. Ambrus A, Nemeria NS, Torocsik B, Tretter L, Nilsson M, Jordan F, Adam-Vizi V (2015) Formation of reactive oxygen species by human and bacterial pyruvate and 2-oxoglutarate dehydrogenase multienzyme complexes reconstituted from recombinant components. Free Radic Biol Med 89:642-650

21. Nemeria NS, Gerfen G, Yang LY, Zhang X, Jordan F (2018) Evidence for functional and regulatory cross-talk between the tricarboxylic acid cycle 2-oxoglutarate dehydrogenase complex and 2-oxoadipate dehydrogenase on the L-lysine, L-hydroxylysine and L-tryptophan degradation pathways from studies in vitro. Biochim Biophys Acta-Bioenerg 1859:932-939

22. Nemeria NS, Gerfen G, Nareddy PR, Yang LY, Zhang X, Szostak M, Jordan F (2018) The mitochondrial 2-oxoadipate and 2-oxoglutarate dehydrogenase complexes share their E2 and E3 components for their function and both generate reactive oxygen species. Free Radic Biol Med 115:136-145

23. Vaubel RA, Rustin P, Isaya G (2011) Mutations in the dimer interface of dihydrolipoamide dehydrogenase promote site-specific oxidative damages in yeast and human cells. J Biol Chem 286:40232-40245

24. Ambrus A, Torocsik B, Tretter L, Ozohanics O, Adam-Vizi V (2011) Stimulation of reactive oxygen species generation by disease-causing mutations of lipoamide dehydrogenase. Hum Mol Genet 20:2984-2995

25. Ambrus A, Wang JJ, Mizsei R, Zambo Z, Torocsik B, Jordan F, Adam-Vizi V (2016) Structural alterations induced by ten diseasecausing mutations of human dihydrolipoamide dehydrogenase analyzed by hydrogen/deuterium-exchange mass spectrometry: implications for the structural basis of E3 deficiency. Biochim Biophys Acta-Mol Basis Dis 1862:2098-2109

26. Park Y-H, Patel MS (2010) Characterization of interactions of dihydrolipoamide dehydrogenase with its binding protein in the human pyruvate dehydrogenase complex. Biochem Biophys Res Commun 395:416-419 
27. Patel MS, Korotchkina LG, Sidhu S (2009) Interaction of E1 and E3 components with the core proteins of the human pyruvate dehydrogenase complex. J Mol Catal B-Enzym 61:2-6

28. Ciszak EM, Makal A, Hong YS, Vettaikkorumakankauv AK, Korotchkina LG, Patel MS (2006) How dihydrolipoamide dehydrogenase-binding protein binds dihydrolipoamide dehydrogenase in the human pyruvate dehydrogenase complex. J Biol Chem 281:648-655

29. Brautigam CA, Wynn RM, Chuang JL, Machius M, Tomchick DR, Chuang DT (2006) Structural insight into interactions between dihydrolipoamide dehydrogenase (E3) and E3 binding protein of human pyruvate dehydrogenase complex. Structure 14:611-621

30. Ambrus A, Tretter L, Adam-Vizi V (2009) Inhibition of the alphaketoglutarate dehydrogenase-mediated reactive oxygen species generation by lipoic acid. J Neurochem 109:222-229

31. Mailloux RJ, Gardiner D, O'Brien M (2016) 2-Oxoglutarate dehydrogenase is a more significant source of $\mathrm{O}_{2} \cdot{ }^{-} / \mathrm{H}_{2} \mathrm{O}_{2}$ than pyruvate dehydrogenase in cardiac and liver tissue. Free Radic Biol Med 97:501-512

32. Quinlan CL, Goncalves RL, Hey-Mogensen M, Yadava N, Bunik VI, Brand MD (2014) The 2-oxoacid dehydrogenase complexes in mitochondria can produce superoxide/hydrogen peroxide at much higher rates than complex I. J Biol Chem 289:8312-8325

33. Tretter L, Adam-Vizi V (2004) Generation of reactive oxygen species in the reaction catalyzed by alpha-ketoglutarate dehydrogenase. J Neurosci 24:7771-7778

34. Starkov AA, Fiskum G, Chinopoulos C, Lorenzo BJ, Browne SE, Patel MS, Beal MF (2004) Mitochondrial alpha-ketoglutarate dehydrogenase complex generates reactive oxygen species. $\mathbf{J}$ Neurosci 24:7779-7788

35. Shi QL, Xu H, Kleinman WA, Gibson GE (2008) Novel functions of the alpha-ketoglutarate dehydrogenase complex may mediate diverse oxidant-induced changes in mitochondrial enzymes associated with Alzheimer's disease. Biochim Biophys Acta Mol Basis Dis 1782:229-238

36. Starkov AA (2013) An update on the role of mitochondrial alphaketoglutarate dehydrogenase in oxidative stress. Mol Cell Neurosci 55:13-16

37. Adam-Vizi V, Tretter L (2013) The role of mitochondrial dehydrogenases in the generation of oxidative stress. Neurochem Int 62:757-763

38. Andreyev AY, Kushnareva YE, Murphy AN, Starkov AA (2015) Mitochondrial ROS metabolism: 10 years later. Biochemistry (Moscow) 80:517-531

39. Andreyev AI, Kushnareva YE, Starkov AA (2005) Mitochondrial metabolism of reactive oxygen species. Biochemistry (Moscow) 70:200-214

40. Rimessi A, Previati M, Nigro F, Wieckowskic MR, Pinton P (2016) Mitochondrial reactive oxygen species and inflammation: Molecular mechanisms, diseases and promising therapies. Int $\mathrm{J}$ Biochem Cell Biol 81:281-293

41. Nemeria NS, Gerfen G, Guevara E, Nareddy PR, Szostak M, Jordan F (2017) The human Krebs cycle 2-oxoglutarate dehydrogenase complex creates an additional source of superoxide/hydrogen peroxide from 2-oxoadipate as alternative substrate. Free Radic Biol Med 108:644-654

42. Fisher-Wellman KH, Gilliam LAA, Lin CT, Cathey BL, Lark DS, Neufer PD (2013) Mitochondrial glutathione depletion reveals a novel role for the pyruvate dehydrogenase complex as a key $\mathrm{H}_{2} \mathrm{O}_{2}$-emitting source under conditions of nutrient overload. Free Radic Biol Med 65:1201-1208

43. Ambrus A, Torocsik B, Adam-Vizi V (2009) Refolding of the human dihydrolipoamide dehydrogenase. Biochem Eng $\mathbf{J}$ $45: 120-125$
44. Ambrus A, Torocsik B, Adam-Vizi V (2009) Periplasmic cold expression and one-step purification of human dihydrolipoamide dehydrogenase. Protein Expr Purif 63:50-57

45. Gazaryan IG, Krasnikov BF, Ashby GA, Thorneley RNF, Kristal BS, Brown AM (2002) Zinc is a potent inhibitor of thiol oxidoreductase activity and stimulates reactive oxygen species production by lipoamide dehydrogenase. J Biol Chem 277:10064-10072

46. Bando Y, Aki K (1991) Mechanisms of generation of oxygen radicals and reductive mobilization of ferritin iron by lipoamide dehydrogenase. J Biochem 109:450-454

47. Massey V, Strickland S, Mayhew SG, Howell LG, Engel PC, Matthews RG, Schuman M, Sullivan PA (1969) The production of superoxide anion radicals in the reaction of reduced flavins and flavoproteins with molecular oxygen. Biochem Biophys Res Commun 36:891-897

48. Huennekens FM, Basford RE, Gabrio BW (1955) An oxidase for reduced diphosphopyridine nucleotide. J Biol Chem 213:951-967

49. Tahara EB, Barros MH, Oliveira GA, Netto LES, Kowaltowski AJ (2007) Dihydrolipoyl dehydrogenase as a source of reactive oxygen species inhibited by caloric restriction and involved in Saccharomyces cerevisiae aging. Faseb J 21:274-283

50. Kareyeva AV, Grivennikova VG, Vinogradov AD (2012) Mitochondrial hydrogen peroxide production as determined by the pyridine nucleotide pool and its redox state. Biochim Biophys Acta Bioenerg 1817:1879-1885

51. Tretter L, Ambrus A (2014) Measurement of ROS homeostasis in isolated mitochondria. Methods Enzymol 547:199-223

52. Brautigam CA, Chuang JL, Tomchick DR, Machius M, Chuang DT (2005) Crystal structure of human dihydrolipoamide dehydrogenase: $\mathrm{NAD}(+) / \mathrm{NADH}$ binding and the structural basis of disease-causing mutations. J Mol Biol 350:543-552

53. Qi F, Pradhan RK, Dash RK, Beard DA (2011) Detailed kinetics and regulation of mammalian 2-oxoglutarate dehydrogenase. BMC Biochem 12:53

54. Liu TC, Korotchkina LG, Hyatt SL, Vettakkorumakankav NN, Patel MS (1995) Spectroscopic studies of the characterization of recombinant human dihydrolipoamide dehydrogenase and its sidedirected mutants. J Biol Chem 270:15545-15550

55. Kim H, Patel MS (1992) Characterization of 2 site specifically mutated human dihydrolipoamide dehydrogenases (His-452-]Gln and Glu-457-]Gln). J Biol Chem 267:5128-5132

56. Klyachko NL, Shchedrina VA, Efimov AV, Kazakov SV, Gazaryan IG, Kristal BS, Brown AM (2005) pH-dependent substrate preference of pig heart lipoamide dehydrogenase varies with oligomeric state - response to mitochondrial matrix acidification. $\mathrm{J}$ Biol Chem 280:16106-16114

57. Visser J, Veeger C (1968) Relations between conformations and activities of lipoamide dehydrogenase. 3. Protein associationdissociation and the influence on catalytic properties. Biochim Biophys Acta 159:265-275

58. Tsai CS, Templeton DM, Wand AJ (1981) Multifunctionality of lipoamide dehydrogenase: activities of chemically trapped monomeric and dimeric enzymes. Arch Biochem Biophys 206:77-86

59. Ambrus A, Mizsei R, Adam-Vizi V (2015) Structural alterations by five disease-causing mutations in the low-pH conformation of human dihydrolipoamide dehydrogenase (hLADH) analyzed by molecular dynamics - implications in functional loss and modulation of reactive oxygen species generation by pathogenic hLADH forms. Biochem Biophys Reports 2:50-56

60. Ambrus A, Adam-Vizi V (2013) Molecular dynamics study of the structural basis of dysfunction and the modulation of reactive oxygen species generation by pathogenic mutants of human dihydrolipoamide dehydrogenase. Arch Biochem Biophys 538:145-155

61. Szabo E, Mizsei R, Wilk P, Zambo Z, Torocsik B, Weiss MS, Adam-Vizi V, Ambrus A (2018) Crystal structures of the 
disease-causing D444V mutant and the relevant wild type human dihydrolipoamide dehydrogenase. Free Radic Biol Med 124:214-220

62. Ambrus A, Friedrich K, Somogyi A (2006) Oligomerization of nitrophorins. Anal Biochem 352:286-295

63. Sakaguchi Y, Yoshino M, Aramaki S, Yoshida I, Yamashita F, Kuhara T, Matsumoto I, Hayashi T (1986) Dihydrolipoyl dehydrogenase deficiency - a therapeutic trial with branched-chain amino acid restriction. Eur J Pediatr 145:271-274

64. Brautigam CA, Wynn RM, Chuang JL, Naik MT, Young BB, Huang TH, Chuang DT (2011) Structural and thermodynamic basis for weak interactions between dihydrolipoamide dehydrogenase and subunit-binding domain of the branched-chain alphaketoacid dehydrogenase complex. J Biol Chem 286:23476-23488

65. Benen J, Vanberkel W, Dieteren N, Arscott D, Williams C, Veeger C, Dekok A (1992) Lipoamide dehydrogenase from Azotobacter vinelandii-site-directed mutagenesis of the His450-Glu455 diad-kinetics of wild-type and mutated enzymes. Eur J Biochem 207:487-497

66. Benen J, Vanberkel W, Veeger C, Dekok A (1992) Lipoamide dehydrogenase from Azotobacter vinelandii-the role of the $\mathrm{C}$-terminus in catalysis and dimer stabilization. Eur $\mathrm{J}$ Biochem 207:499-505

67. Bunik V, Westphal AH, de Kok A (2000) Kinetic properties of the 2-oxoglutarate dehydrogenase complex from Azotobacter vinelandii-evidence for the formation of a precatalytic complex with 2-oxoglutarate. Eur J Biochem 267:3583-3591

68. Reed LJ, Oliver RM (1968) The multienzyme alpha-keto acid dehydrogenase complexes. Brookhaven Symp Biol 21:397-412

69. Massey V (1960) The composition of the ketoglutarate dehydrogenase complex. Biochim Biophys Acta 38:447-460

70. Poulsen LL, Wedding RT (1970) Purification and properties of the a-ketoglutarate dehydrogenase complex of cauliflower mitochondria. J Biol Chem 245:5709-5717

71. Erfle JD, Sauer F (1969) The inhibitory effects of acyl-coenzyme A esters on the pyruvate and a-oxoglutarate dehydrogenase complexes. Biochim Biophys Acta 178:441-452

72. Zhou J, Yang L, Ozohanics O, Zhang X, Wang J, Ambrus A, Arjunan P, Brukh R, Nemeria NS, Furey W, Jordan F (2018) A multipronged approach unravels unprecedented protein-protein interactions in the human 2-oxoglutarate dehydrogenase multienzyme complex. J Biol Chem 293:19213-19227

73. Rice JE, Dunbar B, Lindsay JG (1992) Sequences directing dihydrolipoamide dehydrogenase (E3) binding are located on the 2-oxoglutarate dehydrogenase (E1) component of the mammalian 2-oxoglutarate dehydrogenase multienzyme complex. EMBO J 11:3229-3235

74. McCartney RG, Rice JE, Sanderson SJ, Bunik V, Lindsay H, Lindsay JG (1998) Subunit interactions in the mammalian alpha-ketoglutarate dehydrogenase complex - Evidence for direct association of the alpha-ketoglutarate dehydrogenase and dihydrolipoamide dehydrogenase components. J Biol Chem 273:24158-24164

75. Yan LJ, Thangthaeng N, Sumien N, Forster MJ (2013) Serum dihydrolipoamide dehydrogenase is a labile enzyme. J Biochem Pharmacol Res 1:30-42

76. Constantinescu A, Pick U, Handelman GJ, Haramaki N, Han D, Podda M, Tritschler HJ, Packer L (1995) Reduction and transport of lipoic acid by human erythrocytes. Biochem Pharmacol 50:253-261

77. Reed LJ, Hackert ML (1990) Structure-function relationships in dihydrolipoamide acyltransferases. J Biol Chem 265:8971-8974

78. Jiang ZH, Chen QY, Harrison TJ, Li GJ, Wang XY, Li H, Hu LP, Li KW, Yang QL, Tan C, Fang ZL (2016) Hepatitis B virus core promoter double mutations (A1762T, G1764A) are associated with lower levels of serum dihydrolipoyl dehydrogenase. Intervirology 59:1-7

79. Kunz WS, Gellerich FN (1993) Quantification of the content of fluorescent flavoproteins in mitochondria from liver, kidney cortex, skeletal muscle, and brain. Biochem Med Metab Biol 50:103-110

80. Rapoport M, Saada A, Elpeleg O, Lorberboum-Galski H (2008) TAT-mediated delivery of LAD restores pyruvate dehydrogenase complex activity in the mitochondria of patients with LAD deficiency. Mol Ther 16:691-697

81. Rapoport M, Salman L, Sabag O, Patel MS, Lorberboum-Galski H (2011) Successful TAT-mediated enzyme replacement therapy in a mouse model of mitochondrial E3 deficiency. J Mol Med $89: 161-170$

Publisher's Note Springer Nature remains neutral with regard to jurisdictional claims in published maps and institutional affiliations. 